\title{
A FAVOR DA ESCOLA PÚBLICA: a intersetorialidade como premissa para a educação inclusiva ${ }^{1}$
}

\author{
Márcia Denise Pletsch \\ Miriam Ribeiro Calheiros de Sá \\ Geovana Mendonça Lunardi Mendes
}

Resumo

Neste artigo, discute-se a importância da intersetorialidade como premissa para a educação inclusiva de crianças com deficiência múltipla e o papel da escola pública nesse processo. Uma pesquisa qualitativa foi realizada por meio de entrevistas semiestruturadas com profissionais da Educação, Assistência Social e Saúde de três municípios da Baixada Fluminense e dois do Sul Fluminense, Rio de Janeiro. Os dados indicam que existe uma preocupação por parte dos gestores municipais em efetuar ações integradas e intersetoriais. Apontam, também, que, em grande medida, faltam condições de recursos humanos e diretrizes claras sobre como proceder para efetivar ações intersetoriais para a promoção integral dessas crianças, considerando a sua matrícula em turmas comuns das redes de ensino. Ressalta-se, assim, a importância da escola como espaço potencialmente capaz de mobilizar e articular ações mais integradas entre as diferentes áreas da política social.

Palavras-chave: educação inclusiva; deficiência múltipla; intersetorialidade.

IN FAVOR OF THE PUBLIC SCHOOL: intersectionality as a premise for inclusive education

\begin{abstract}
In this paper, the importance of intersectionality as a premise for the inclusive education of children with multiple disabilities and the role of the public school in this process is discussed. A qualitative research was carried out through semi-structured interviews with Education, Social Assistance and Health professionals from three municipalities in the Baixada Fluminense, and two in the Sul Fluminense, Rio de Janeiro, Brazil. The data indicate that there is a concern on the part of municipal managers to carry out integrated and intersectoral actions. They also point out that, to a large extent, there is a lack of human resources conditions and clear guidelines on how to proceed to carry out intersectoral actions for the integral promotion of these children, considering their enrollment in common groups of the education networks. Thus, the importance of the school as a space potentially capable of mobilizing and articulating more integrated actions between the different areas of social policy is emphasized.
\end{abstract}

Keywords: inclusive education; multiple disabilities; intersectoral actions.

\footnotetext{
${ }^{1}$ Projeto financiado pelo Conselho Nacional de Desenvolvimento Científico e Tecnológico (CNPq) e pela Fundação Carlos Chagas Filho de Amparo à Pesquisa do Estado do Rio de Janeiro (FAPERJ) (Edital Jovem Cientista do Nosso Estado e Edital Grupos Emergentes Processo E-26/010.002186/2019).
} 
DOI: $10.12957 /$ teias.2021.58619

\section{A FAVOR DE LA ESCUELA PÚBLICA: la intersectorialidad como premisa para la educación inclusiva}

Resumen

En este artículo se discute la importancia de la intersectorialidad como premisa para la educación inclusiva de niños con discapacidades múltiples y el rol de la escuela pública en este proceso. Una investigación cualitativa fue realizada por medio de entrevistas semiestructuradas con profesionales de la Educación, Asistencia Social y Salud de tres municipios de Baixada Fluminense y dos de Sur Fluminense, estado de Rio de Janeiro, Brasil. Los datos indican que existe una preocupación por parte de los gestores municipales por realizar acciones integradas e intersectoriales. Señalan también que, en gran medida, faltan condiciones de recursos humanos y lineamientos claros sobre cómo proceder para llevar a cabo acciones intersectoriales para la promoción integral de estos niños, considerando su matrícula en clases comunes de las redes de enseñanza. Se resalta, así, la importancia de la escuela como un espacio potencialmente capaz de movilizar y articular acciones más integradas entre las distintas áreas de la política social.

Palabras clave: educación inclusiva; discapacidades múltiples; intersectorialidad.

\section{INTRODUÇÃO E REFERENCIAIS TEÓRICOS}

A escola pode ser pequena e remota, mas para muitos estudantes é o centro do mundo, o espaço onde a esperança sobrevive para muitas pessoas subjugadas pela pobreza e pela ignorância, ambas filhas da injustiça e da opressão; a escola e seus protagonistas formam um mural esculpido no mármore da coragem e do compromisso (CAIVANO, 2001, p. 12-13).

Em março de 2021, completou um ano que a Organização Mundial da Saúde (OMS) declarou a pandemia provocada pela COVID-19, o nomeado "novo coronavírus" (SARS-CoV-2). Os impactos sociais, econômicos, sanitários, políticos e científicos ainda não são mensuráveis diante das milhares de vidas perdidas. No Brasil, o sistema de saúde está em colapso em várias partes do país e convivemos, até a escrita deste texto, com o peso das mais de 350 mil mortes registradas.

Além da crise sanitária na saúde, a ampliação do desemprego e das desigualdades sociais, o país também enfrenta a maior crise da história no sistema educacional público. Há um ano a maioria das crianças e dos jovens não tem aulas presenciais ou tem aulas remotas com enormes prejuízos para o seu desenvolvimento, em decorrência da precariedade de acesso aos recursos tecnológicos e à internet (SATO, 2020; UNESCO, 2020; 2020a). Sem contar os prejuízos emocionais e sociais provocados pelo isolamento social. Tomando esse cenário como ponto de partida, este artigo discute o papel da escola pública e de ações intersetoriais como premissa para a educação inclusiva de crianças com deficiência múltipla².

A análise sobre a escolarização e o desenvolvimento de crianças com deficiência múltipla tem sido objeto de pesquisa do Observatório de Educação Especial e Inclusão Educacional

\footnotetext{
2 A deficiência múltipla é caracterizada como “[...] uma condição heterogênea que identifica grupos de pessoas, revelando associações diversas de deficiência que afetam, mais ou menos intensamente, o funcionamento individual e o relacionamento social" (BRASIL, 2000, p. 47).
} 
$(\mathrm{ObEE})^{3}$ e de seus parceiros interinstitucionais, como o Observatório de Práticas Escolas (OPE) ${ }^{4}$, desde 2012 (PLETSCH, 2015; PLETSCH, MENDES, HOSTINS, 2015; PLETSCH, ROCHA, OLIVEIRA, 2020; ROCHA, 2014, 2018). A partir de 2018, ampliamos nossas investigações também para crianças com deficiência múltipla acometidas pela infecção do Zika vírus durante a epidemia ocorrida no Brasil, de forma mais intensa nos anos de 2015 e 2016 (PLETSCH, MENDES, 2020; SÁ, PLETSCH, 2021). Importante mencionarmos que, em geral, crianças com deficiência múltipla e, principalmente, aquelas que possuem a Síndrome Congênita do Zika Vírus (SCZV) apresentam, também, em sua maioria, problemas crônicos complexos de saúde como apontado por Sá e Pletsch (2021). A Condição Crônica de Saúde (CCS) tem sido discutida desde os anos de 1990 pela OMS, englobando doenças crônicas, infecciosas e as mais variadas deficiências, as quais envolvem em sua avaliação aspectos como temporalidade e continuidade do cuidado, controle de sintomas e longitudinalidade da atenção, intervenção e suporte/apoio (MOREIRA et al., 2017; OMS, 2003; SÁ, PLETSCH, 2021).

Os resultados de nossas investigações com crianças com deficiência múltipla têm mostrado, entre outros aspectos, o papel das mulheres-mães, a importância de suportes educacionais mais estruturados, assim como de ações intersetoriais para o desenvolvimento integral dessas crianças. Nesse sentido, os dados da pesquisa têm sinalizado para a importância da escola e a forma positiva como ela afeta na participação e no desenvolvimento dessas crianças. A matrícula em turmas comuns de ensino regular, conforme previsto nas políticas de educação inclusiva, também tem sido relatada pelas mães e pelos profissionais da educação como fundamental para a interação e o desenvolvimento dos filhos (SÁ, PLETSCH, 2021).

Em um dos depoimentos, uma mãe ressaltou a importância de a escola ser um espaço de acolhimento: "Eu tinha muito medo de colocar o meu filho na escola, mas a escola abraçou a mim e ao meu filho" (Entrevista com uma das mães de uma criança com SCZV, em fevereiro de 2021). Acolher a diversidade humana parece ser uma das funções sociais mais importantes da escola (DAINES, SMOLKA, 2019), pois é na interação com a diferença que nos constituímos humanos, conforme preconizado pela perspectiva histórico-cultural de Vygotski (1997) e, também, pela teoria bioecológica de Urie Bronfenbrenner (2021).

A educação inclusiva, como destacado na Política Nacional de Educação Especial na Perspectiva da Educação Inclusiva (PNEEPEI, BRASIL, 2008, p. 5), é uma:

[...] ação política, cultural, social e pedagógica, desencadeada em defesa do direito de todos os alunos de estarem juntos, aprendendo e participando, sem nenhum tipo de discriminação. A educação inclusiva constitui um paradigma educacional fundamentado na concepção de direitos humanos, que conjuga igualdade e diferença como valores indissociáveis.

O termo educação inclusiva é polissêmico e pode ser interpretado e conceituado de forma ampla, referindo-se a diferentes grupos sociais historicamente excluídos da escola. No caso específico do público deste artigo, compreendemos que os sujeitos devem ter acesso à educação, participar das atividades educativas e aprender. Isso implica a combinação de três elementos: 1) o reconhecimento da diferença como constitutiva do humano; b) as especificidades no

3 O Observatório de Educação Especial e Inclusão Educacional (ObEE) é vinculado ao Centro de Inovação Tecnológica e Educação Inclusiva (CITEI) do Instituto Multidisciplinar - Campus da UFRRJ de Nova Iguaçu. Ver http://obee.ufrri.br.

4 O Observatório de Práticas Escolares (OPE) é vinculado ao Programa de Pós-Graduação em Educação da Universidade do Estado de Santa Catarina (UDESC). Ver https://ope.education/. 
desenvolvimento dos sujeitos; e 3) a convivência com a diversidade cultural, em uma escola/universidade com todos e para todos (PLETSCH, 2020; PLETSCH, SOUZA, 2021).

Os benefícios da escolarização em turmas plurais, as chamadas inclusivas, não são novidade para crianças com deficiências em geral. O que nossas pesquisas têm mostrado é como a entrada de crianças com comprometimentos mais severos tem sido afetada de forma positiva, principalmente se tomarmos como referência a compreensão da deficiência a partir da funcionalidade humana em detrimento do modelo médico, biologizante. A Classificação Internacional de Funcionalidade, Incapacidade e Saúde (CIF) (International Classification of Functioning, Disability and Health) foi introduzida pela OMS em 2001 para substituir o uso do "velho" Código Internacional de Doenças (CID), para explicar a funcionalidade das pessoas com deficiências na sociedade e nos espaços educacionais (OMS, 2007). Assim, ganhou destaque a questão da acessibilidade e suas diferentes dimensões em detrimento do modelo anterior, que focava na adaptação e classificava as pessoas em "normais" e "anormais", com base em padrões homogeneizantes que desconsideravam a diversidade humana.

A compreensão do fenômeno da deficiência a partir do modelo social e de direitos significou um considerável avanço conceitual, pois tirou o foco dos impedimentos do sujeito e centrou o debate no papel social e nas possibilidades dessas pessoas. Desde então, os avanços científicos e políticos consistem justamente em entender a deficiência não como um atributo da pessoa, mas como resultado da interação social. Desse modo, o problema não está na deficiência em si, mas em ambientes inacessíveis que criam barreiras à participação plena dessa população.

Outro dado de nossas investigações tem sido o reconhecimento do trabalho colaborativo entre os diferentes profissionais (educação, assistência social e saúde) com as famílias dessas crianças para compartilhar informações, conhecimentos para além das fronteiras disciplinares de cada área com o objetivo de efetivar programas de intervenção para a promoção do desenvolvimento integral (SÁ et al., 2019; SÁ, PLETSCH, SOUZA, 2021).

A potencialidade da escola como espaço mobilizador de ações intersetoriais tem sido empregada em diferentes países do mundo pela sua expressividade sociodemográfica relacionada à infância e à adolescência, mas também como espaço de enfrentamento de vulnerabilidades sociais (CARVALHO, 2012; GIONGO, 2019; PAHO, WHO, 2016; SOUZA, 2017; VIEIRA, BELISÁRIO, 2018). Aliás, em países altamente desiguais como é o caso do Brasil, a escola acaba assumindo não apenas o processo educacional da maioria da população, mas é também a responsável pela integridade física e segurança alimentar de milhares de crianças e de jovens, o que expressa a desigualdade social e a precarização das políticas de proteção social (ALMEIDA FILHO, 2021; ANPEd, 2021). A ampliação das desigualdades sociais e educacionais neste momento histórico amplia a importância de ações intersetoriais entre os diferentes instrumentos públicos para efetivar políticas e programas de proteção social e prevenção da disseminação do vírus - COVID-19.

A intersetorialidade é compreendida como uma relação entre uma ou várias partes de setores que tenham se organizado para atuar em um tema, com vistas a atingir resultados de uma maneira mais efetiva e sustentável do que poderia alcançar um setor agindo por si só. Acreditamos que as articulações e os arranjos podem ocorrer por meio da construção de parcerias entre diferentes setores e segmentos sociais como: educação, saúde, assistência social, cultura, esporte, lazer, empresas privadas, organizações não-governamentais (ONGs), fundações, entidades religiosas, as três esferas de governo (Federal, Estadual e Municipal), organizações comunitárias, dentre outros (TEIXEIRA, PAIM, 2002; WIMMER, FIGUEIREDO, 2006). 
No âmbito das políticas públicas e sociais, as focalizadas, as quais, muitas vezes, propõem ou se ancoram na intersetorialidade, são vistas como políticas que ajudam a conviver com os processos de exclusão gerados pela acumulação do capital. No entanto, no auge da crise sanitária e humanitária que estamos vivendo, a intersetorialidade se coloca premente, como uma alternativa possível para conseguirmos avançar em termos de respostas políticas efetivas para a garantia dos direitos humanos.

Nesse sentido, a própria noção de justiça obriga-nos a buscar uma compreensão intersetorial. Conforme afirma Fraser (2006, p. 232), podemos compreender de duas formas, de maneira muito genérica, o conceito de injustiça, "[...] a primeira delas é a injustiça econômica, que se radica na estrutura econômico-política da sociedade [...]. A segunda maneira de compreender a injustiça é cultural ou simbólica. Aqui a injustiça se radica nos padrões sociais de representação, interpretação e comunicação". A busca pela resposta intersetorial na perspectiva da educação inclusiva é a tentativa de superação dessas injustiças e exclusões que se ampliaram significativamente com a pandemia, sobretudo no campo educacional como evidenciam dados internacionais (UNESCO, 2020, 2020a; DUSSEL, 2020) e nacionais (GUIMARÃES, 2020).

No caso específico deste artigo, que trata de pessoas com deficiência múltipla, exis tem diferentes equipamentos sociais e projetos importantes para promover os direitos sociais e educacionais, assim como a qualidade de vida dessa parcela da população. Todavia, de maneira geral, a rede identificada de atenção à saúde e à educação dessas crianças não tem se articulado intersetorialmente, caracterizando-se, portanto, como uma rede multisetorial. Essa constatação fundamenta-se no fato de que a maioria das ações e dos serviços prestados são planejados por um único setor ou equipamento social para serem aplicados junto a outros. Em seu estudo, Silva e Rodrigues (2010) evidenciaram que falta consenso entre os setores Educação, Assistência Social e Saúde sobre como atuar de forma mais integrada, o que acaba provocando entraves que se opõem à organização de ações intersetoriais necessárias para o desenvolvimento integral dessas crianças.

Nessa acepção, consideramos o Programa Estratégia de Saúde da Família (ESF), "porta de entrada" para o sistema de saúde, como importante aliado nessa construção da atenção integral a crianças com deficiência múltipla e suas famílias, uma vez que essa estratégia coloca as famílias nas agendas das políticas sociais. No ESF, os trabalhadores estabelecem interfaces entre si e com os usuários em distintos e inusitados espaços (unidade de saúde da família; unidades básicas de saúde, domicílios, escolas, ruas, igrejas, dentre outros), muitas vezes além do território de adscrição, configurando-se em um complexo mosaico que pressupõe o entendimento de um trabalho interdisciplinar e interconectado pelos diferentes saberes, culturas e práticas (ASSIS et al., 2007; DIAS et al., 2014).

Não podemos deixar de mencionar, também, o Programa Saúde na Escola (PSE), criado em 2007, pelos Ministérios da Saúde e Educação. Esse Programa articula a atenção básica à saúde e ao Ensino Fundamental, propondo ações conjuntas de intervenção que melhoram a qualidade de vida das pessoas e os indicadores educacionais e de saúde a partir das demandas locais dos territórios. Aqui, parece-nos que a escola, pelo papel central que ocupa na vida das famílias e das comunidades em que se localiza, é o espaço por excelência para estruturar ações intersetoriais, principalmente no caso do atendimento integral de crianças com deficiência múltipla (PLETSCH, ARAUJO, ROCHA, 2020; SÁ, PLETSCH, 2021; VIEIRA, BELISÁRIO, 2018).

Em outras palavras, acreditamos que a articulação entre o PSE e o ESF poderia favorecer a construção de uma estratégia de cuidado ampliado, que se solidificaria por meio das interrelações, na busca pela construção de um projeto de cuidado singular para cada uma dessas crianças e suas famílias, considerando diversos aspectos que envolvem as demandas e as necessidades de maneira 
particular e integrada (CAMPOS, 2011; SANTOS, MISHIMA, MERHY, 2018). Uma ação integrada entre as linhas de cuidado voltadas à saúde da criança e da pessoa com deficiência - a partir das unidades da Atenção Primária em Saúde (APS), que têm a responsabilidade da coordenação do cuidado e o ordenamento da rede de saúde, e o PSE, que em sua origem tem como principal foco preconizar ações intersetoriais e mobilizar parceiros, à procura de qualificar o cuidado individual e coletivo - poderiam favorecer ações de promoção da saúde e inclusão social de crianças com deficiências múltiplas e suas famílias.

Nessa perspectiva, a articulação intersetorial teria como fio condutor, perpassando transversalmente todas as ações, o modelo do Cuidado Centrado na Família (CCF), que o Institut for Patient - and Family-Centered-Care (IPFCC) caracteriza por:

[...] uma abordagem para planejamento, entrega e avaliação de cuidados de saúde que se baseia em parcerias mutuamente benéficas entre prestadores de cuidados de saúde, pacientes e famílias. Ele redefine os relacionamentos nos cuidados de saúde, dando ênfase à colaboração com pessoas de todas as idades, em todos os níveis de atendimento e em todas as configurações de cuidados de saúde. (IPFCC, 2014, n.p.).

Van Veelen et al. (2017), em seu estudo, refletem sobre a noção de cuidados centrados na criança e na família como papel fundamental de fornecer cuidados integrados para crianças que precisam de proteção, de forma a superar a fragmentação no sistema de bem-estar infantil reservado a gerenciamento de casos. Como pontos da abordagem realizada no estudo, os gestores de casos concordaram que tiveram de aprender mais sobre a criança e a família, considerando os problemas complexos e recorrentes e investindo em um relacionamento com a família. O intuito era aprofundar o sistema familiar e adotar uma perspectiva mais integrada (padrões de comportamento, interação e comunicação) para encontrar as causas dos problemas.

É importante destacarmos que a educação para a implementação do CCF precisa garantir que o modelo de cuidado ${ }^{5}$ destinado a apoiar as necessidades das famílias e atendê-las não seja interpretado como um modelo que coloca a responsabilidade indesejada aos pais, além dos esforços já basilares para cuidado de crianças (HODGETTS et al., 2013). Segundo Moreira et al. (2019), as famílias já se encontram sobrecarregadas no que toca aos cuidados gerais de seus filhos; assim, há de observar-se que o modelo de CCF pressupõe a participação da família na construção coletiva desse cuidado. Esse modelo busca o atendimento das necessidades não apenas clínicas, mas também emocionais, afetivas, educacionais e sociais, possibilitando um cuidado mais abrangente.

Acreditamos que a abordagem do CCF, se bem compreendida, pode ser incorporada na realidade do cuidado e do desenvolvimento integral da criança, para além da perspectiva da saúde. Nossas investigações com crianças com deficiências múltiplas severas têm indicado que a organização de ações e estratégias centradas na família são um caminho necessário para garantir não apenas os direitos sociais, mas também para efetivar: a) programas de intervenção educacional na área da comunicação alternativa para aquelas que não são oralizadas com as suas famílias de forma articulada com os professores; e b) programas de intervenção junto às famílias para aumentar a participação das crianças no ambiente domiciliar como fator de desenvolvimento da funcionalidade (PLETSCH, 2019; SÁ, PLETSCH, 2021). Nosso pressuposto é de que o fortalecimento de ações intersetoriais entre educação, assistência social e saúde proporciona maior

\footnotetext{
${ }^{5}$ Não é nosso objetivo, neste artigo, retomar a discussão sobre o conceito de cuidado aqui empregado. Para tal, sugerimos as leituras de Böck, Gomes e Beche (2020), Fietz e Mello (2018) e Sá e Pletsch (2021).
} 
oferta, oportunidade e reforça as capacidades existentes nos equipamentos educacionais, promovendo inclusão escolar e promoção da qualidade de vida das crianças e de seus familiares.

Contudo, como os municípios estruturam suas propostas para atender as demandas dessas crianças e de outras que chegam às redes públicas de ensino? Quais são as percepções dos profissionais que atuam na educação, assistência social e saúde sobre a intersetorialidade? Quais são os desafios enfrentados localmente para implementar ações nessa direção? Que políticas podem ser implementadas para efetivar programas intersetoriais de atenção e de desenvolvimento integral de crianças com deficiência múltipla, seja em decorrência da SCZV, síndromes raras ou outra condição vinculada à CCS?

\section{ASPECTOS ÉTICOS E METODOLÓGICOS DA PESQUISA}

Para discutir as questões anunciadas no final do tópico anterior, apresentamos, a seguir, dados de uma investigação em andamento. A pesquisa qualitativa desenvolvida de forma colaborativa com os participantes do Fórum Permanente de Educação Especial na Perspectiva Inclusiva da Baixada e Sul Fluminense ${ }^{6}$ integra uma das etapas do projeto multidisciplinar que articula 55 pesquisadores de diferentes instituições (Universidade Federal Rural do Rio de Janeiro - UFRRJ; Universidade do Estado do Rio de Janeiro - UERJ; Pontifícia Universidade Católica do Rio de Janeiro - PUC-Rio; Universidade do Estado de Santa Catarina - UDESC; Fundação Oswaldo Cruz - Fiocruz; Escola Nacional de Saúde Pública - ENSP; e Instituto Fernandes Figueira - IFF) para desenvolver estudos e ações intersetoriais entre educação, assistência social e saúde na promoção da escolarização e do desenvolvimento de crianças com SCZV na Baixada e Sul Fluminense, Rio de Janeiro. O projeto foi aprovado no Comitê de Ética da UFRRJ, Protocolo n. 135/2021, Processo n. 23083.031153/2019-40.

O projeto está sendo desenvolvido em três eixos interligados entre si: Criança e Família; Escola e Professores e Intersetorialidade. Este último é foco deste artigo, por meio do qual analisamos as percepções de profissionais da educação, assistência social e saúde sobre intersetorialidade de três municípios da Baixada Fluminense e um do Sul Fluminense. As entrevistas semiestruturadas foram realizadas com a presença de cada uma das equipes dessas áreas indicadas pelos municípios, por meio digital online, utilizando a plataforma Zoom em função da pandemia provocada pela COVID-19.

A discussão dos dados está ancorada na ideia de que a ação colaborativa entre os diferentes participantes é fundamental para produzir conhecimento e construir indicadores sobre as possibilidades das ações intersetoriais para o desenvolvimento integral de crianças com deficiência múltipla. Em outros termos, nosso propósito com essas entrevistas foi produzir conhecimento com os atores participantes e não sobre eles e suas ações profissionais. Para os excertos analisados, identificamos de forma aleatória cada munícipio por meio de numerais, de forma a garantir a não identificação.

A partir desses princípios, nossa discussão dos dados focará as perspectivas dos profissionais entrevistados sobre a realidade e as ações desenvolvidas em seus territórios e as possibilidades de ações e de propostas intersetoriais de atenção e de desenvolvimento integral de

\footnotetext{
${ }^{6}$ Criado em 2015, no âmbito do Observatório de Educação Especial e Inclusão Educacional (ObEE), o Fórum integra atualmente gestores de Educação Especial de redes de ensino de Municípios da Baixada e Sul Fluminense, assim como pesquisadores da UFRRJ, Campus de Nova Iguaçu, e da UERJ, Campus de Duque de Caxias.
} 
DOI: $10.12957 /$ teias.2021.58619

crianças com deficiência múltipla, seja em decorrência da SCZV, síndromes raras ou outra condição vinculada à CCS.

\section{O DESENVOLVIMENTO INTEGRAL DE CRIANÇAS COM DEFICIÊNCIA MÚLTIPLA: A INTERSETORIALIDADE E O NECESSÁRIO DIÁLOGO COM A ESCOLA}

Os dados revelaram que existe uma preocupação por parte dos gestores municipais em efetuar ações integradas e intersetoriais. Também indicaram que, em grande medida, faltam diretrizes claras sobre como proceder para efetivar ações intersetoriais para a promoção integral das crianças, considerando a sua matrícula em turmas comuns das redes de ensino. Sinalizaram que, de maneira geral, resolvem os desafios e os problemas quando aparecem. A esse respeito um dos entrevistados disse que a "[...] comunicação acaba sendo realizada por meio de telefone ou Whats App entre os diferentes profissionais envolvidos para buscar soluções e não a partir de uma ação sistematizada e planejada de forma intersetorial" (Entrevista realizada em março de $2021 \mathrm{com}$ a equipe do Município 1).

Outro aspecto revelado nas falas dos entrevistados refere-se à importância da escola como espaço potencialmente capaz de mobilizar e articular ações mais integradas entre as diferentes áreas da política social com foco na família, como pode ser observado nas falas dos entrevistados de diferentes municípios:

O discurso de trazer a família, que estimula [a criança] sem ter recurso é fundamental. $\mathrm{O}$ pessoal fica muito preso à fisioterapia, que a terapia tem que ter isso, tem que ter aquilo. A gente tem que ter a caixa de papelão, é brinquedo comum, é ensinar a postura por meio de brincadeiras (referindo-se a um projeto de estimulação essencial). Então, eu acho que a escola, que fica muitas vezes mais tempo com a criança do que a própria mãe, tem tudo a ver com esse trabalho [de estimulação]. (Entrevista realizada em março de 2021 com o Município 3).

Nesse projeto, nós ficávamos com as crianças [em uma sala separada], e foi feito um trabalho muito positivo [com as famílias] que tem resultados até hoje. Essas mães participam até do conselho escolar ativamente, porque a partir da participação tomaram consciência e [viram] que é importante também a atuação da Educação nesse momento com seus filhos. (Entrevista realizada em março de 2021 com o Município 2).

Então, para 2021, a gente tem falado muito em todas as reuniões semanais com o prefeito para abrir um campo no nosso sistema de matrícula para que a gente visualize os exames e os atendimentos desses alunos, até para que auxiliares de secretaria da escola consigam acompanhar esses estudantes. (Entrevista realizada em março de 2021 com o Município 3).

Eles priorizam a Saúde, eles priorizam o benefício de prestação continuada (BPC) e de cesta básica, porque envolve a sobrevivência, e a gente entende isso, mas uma sobrevivência sem uma qualidade de vida que eu creio passa pela Educação, porque a Educação tem esse papel de transformar e de melhorar a vida. (Entrevista realizada em março de 2021 com o Município 1).

Como podemos depreender das falas coligidas, a escola é tomada como referência para o desenvolvimento das crianças com deficiência. A crítica ao modelo médico e biologizante, cujo foco são as características físicas das crianças com deficiência, é sinalizada quando a entrevista diz 
que "o pessoal fica preso à terapia". O foco na terapia e na reabilitação em detrimento da intervenção educacional também foi constatado em fase anterior de nossa investigação, durante as entrevistas com mães de crianças com deficiência múltipla. Os relatos indicaram que as famílias, entre a terapia e a escola, acabam escolhendo a primeira opção. Dessa forma, as crianças que mais precisam de intervenção educacional por meio da comunicação alternativa, por exemplo, acabam faltando na escola porque muitos tratamentos terapêuticos são agendados no mesmo horário (SÁ, PLETSCH, 2021), evidenciando a falta de diálogo entre os diferentes setores que atuam com essa criança.

Ainda sobre tal tema, nossas pesquisas na área de deficiência múltipla têm evidenciado que a promoção do desenvolvimento integral, melhora da participação e consequente autonomia desses sujeitos requer ações intersetoriais, considerando tanto aspectos da saúde quanto da escola e da assistência. Nossos dados indicaram que a escola tem papel determinante ao oferecer atividades educacionais que possibilitem a apropriação de conceitos, seus significados e sentidos, os quais são centrais na estruturação da comunicação e, por consequência, na organização do pensamento e da linguagem e no desenvolvimento do sistema simbólico (PLETSCH, 2015; SÁ, PLETSCH, 2021). Aliás, essa é a função da escola: promover mediações pedagógicas na interação uns com os outros de forma a constituirmo-nos humanos na e com a diferença e a pluralidade presente nas salas de aulas.

Entretanto, essa concepção não foi unanimidade durante as entrevistas com participantes da mesma equipe. Também tivemos relatos que ainda tomam o modelo médico e biologizante da deficiência como base para o planejamento de ações e intervenção junto às famílias. Vejamos:

O que é microcefalia? O que é Síndrome Congênita? Como se deu isso? O que é Zika vírus? E essa questão do conceito da doença, da biologia, pra gente foi muito novo. Então para poder estar atendendo essas famílias eu preciso entender um pouco a doença, biologicamente, como é que se deu isso. Eu tenho discutido aqui da gente poder estudar a questão mesmo biológica, o conceito da doença. (Entrevista realizada em março de 2021 com o Município 3).

A visão biológica de compreensão da deficiência é histórica e muito presente na cultura e nos discursos sociais e escolares. Essas concepções têm contribuído para fomentar ações intersetoriais centradas no uso e na distribuição de medicamentos para pessoas com deficiências. O relato a seguir exemplifica nossa interpretação:

A gente tem feito hoje um levantamento dos medicamentos que os nossos alunos utilizam porque o uso de medicamentos [...] é muito grande e a gente precisa ter como conferir se o município atende todos os medicamentos ou se tem alunos com problemas de retirada de medicamento ou não faz parte do sistema de distribuição. (Entrevista realizada em março de 2021 com o Município 4).

Os entrevistados também trouxeram à tona a relevância do desenvolvimento de mecanismos de diálogos entre os diferentes níveis de atenção, principalmente dentro dos municípios e com os demais entes federativos (Estado e União), na direção de um alinhamento dos programas já existentes. Nessa perspectiva, para atender as demandas colocadas pela SCZV, um dos municípios sinalizou: "Por isso, nós [município] criamos um grupo de trabalho que chamávamos de GT Intersetorial" e continua:

Então, o Estado fez essa ponte e a gente vem tendo reunião trimestral com o Estado com relação ao zika e o storch, e os noventa e dois municípios estão 
envolvidos e aí foi pensado nessas reuniões [pelo município] a criação de um comitê intersetorial para as crianças e famílias em situação de vulnerabilidade com crianças de zika e o storch. A partir disso, estamos fazendo o acompanhamento via assistência social e criamos pontos focais na Saúde, Educação e Assistência para colocar em contato as pessoas envolvidas para ampliar o diálogo e criar essa comissão intersetorial. (Entrevista realizada em março de 2021 com o Município 2).

Destacamos, aqui, que, após a emergência sanitária causada pela magnitude dos casos de crianças com deficiência múltipla em decorrência das infecções congênitas causadas pelo Zika vírus, a OMS solicitou aos Estados brasileiros a produção de um plano de enfrentamento da infecção pelo vírus e outras condições infecto contagiosas (BRASIL, 2017). Para fortalecer a necessidade da atenção integral a essas crianças, por exemplo, em julho de 2016, o estado do Rio de Janeiro lançou uma nota técnica apontando que o planejamento de ações de intervenção com essas crianças deve correr junto às famílias (RIO DE JANEIRO, 2016). O documento que dispõe sobre a atuação intersetorial para atenção dos casos de microcefalia entre a rede de saúde e assistência social propôs um plano de enfrentamento que dispunha, entre outras ações, de atividades educativas para profissionais de saúde, da assistência social e profissionais atuantes na atenção primária.

Em que pese a importância dessa ação, chama atenção a ausência da educação como área essencial para apoiar as medidas a serem implementadas no campo intersetorial. Talvez, a replicação desse modelo pelos municípios aqui entrevistados tenha afetado um planejamento integrado que favoreceria o atendimento intersetorial e integral de todas as crianças com deficiência múltipla que demandam os serviços do sistema público.

Outro dado que foi observado a partir das falas dos gestores é que essa iniciativa entre saúde e assistência, em alguns momentos, não foi continuada, por diversas razões que podem ser aqui discutidas, tais como: troca de profissionais das equipes que estavam atuando nessa construção intersetorial; demandas urgentes que precisaram ser resolvidas, dentre outras. A fala, a seguir, ilustra essa questão ao novamente focar a educação como um espaço de articulação entre os demais instrumentos públicos do município:

Realmente a gente sabe das dificuldades de unir as várias Secretarias, pela educação, qualquer outra demanda que precisa de serviços da saúde e assistência. A educação acaba recebendo os alunos e o trâmite todo passa pela Secretaria da Educação que recebe os alunos encaminhados pelas escolas e, depois, articula com os outros serviços demandados. (Entrevista realizada em março de 2021 com o Município 4).

Também ficou claro nos relatos que, devido a carência de pessoal para formar as equipes, a rotatividade de pessoas dentro das secretarias e as demandas emergentes e constantes, a continuidade das ações fica muito comprometida. A esse respeito, o trecho a seguir é ilustrativo:

A gente não faz mais outra coisa, a gente não consegue vislumbrar nada para o futuro próximo que seja mediante as ações que estão sendo realizadas. As dificuldades são muitas, e a gente apaga incêndios o tempo todo, sem condições humanas para dar conta de tantas demandas. Ou seja, nós trabalhamos de acordo com a demanda, a gente vai resolvendo. (Entrevista realizada em março de 2021 com o Município 4). 
Em síntese, os dados revelam a necessidade de ações intersetoriais para promoção do desenvolvimento integral de pessoas com deficiência múltipla, seja em decorrência da SCZV, síndromes raras ou outra condição vinculada à CCS. Igualmente, reconhecem o papel da escola como agente importante no processo das articulações entre os diferentes instrumentos públicos.

\section{CONSIDERAÇÕES FINAIS}

A diversidade nos assusta e tendemos a compreendê-la como indício de desordem o fracasso de aprendizagem, ambas, situacões que tentaremos evitar organizando turmas ideais, homogêneas, cheias de alunos iguais uns aos outros. Tudo em vão, naturalmente, pois escolas - tal como tudo mais relacionado à Educação - são fenômenos com vida e alma próprias, livres e absolutamente fora do nosso controle, fenômenos cuja existência depende do diverso, do imprevisivel acaso. (SENNA, 2014, p. 58).

Ao longo deste artigo, evidenciamos que o PSE e o ESF podem favorecer a construção de ações e de programas centrados no cuidado e na família, considerando diversos aspectos que envolvem as demandas e as necessidades de maneira particular e integrada. Infelizmente, a pesquisa mostrou que a pandemia tem prejudicado as iniciativas planejadas pelos municípios, principalmente com a chegada, na escola, das crianças com deficiência múltipla em consequência da SCZV, como indica o trecho a seguir:

Agora, no caso dos alunos com a síndrome congênita do Zika vírus, estou chateada, pois a pandemia esfriou, jogou um balde de água fria no nosso projeto enquanto equipamentos e ações intersetoriais. Nós estamos gestando esse projeto desde 2017, com diferentes personagens e diferentes atores, e conseguimos avançar, mas com a pandemia o foco tem sido atender as demandas do COVID. (Entrevista realizada em março de 2021 com o Município 3).

Os dados também revelaram que pensar políticas e programas intersetoriais de forma preventiva é pensar "o futuro desse sujeito" (Em entrevista realizada em março de 2021 com o Município 3). Nessa direção, o diálogo entre saúde e assistência com a escola mostra-se fundamental para avançarmos nos indicadores sociais, educacionais e de saúde da população, de modo a garantir os direitos humanos preconizados em nossa Constituição. A esse respeito, acompanhar e incentivar ações a partir da proposta do Programa Saúde na Escola parece ser um bom começo.

Ademais, uma das principais críticas que a educação inclusiva como proposta tem recebido é sua dificuldade de modificar os contextos de desigualdade sociais. Nesse sentido, parece-nos que a intersetorialidade pode ser um caminho para tocar em um conjunto de desigualdades estruturantes da condição de vida das crianças com deficiência múltipla e suas famílias. Além disso, diante de tudo que estamos vivendo, acreditamos no potencial republicano da Escola Pública para ajudar na reconstrução do país. A escola é o principal espaço em que poderemos, com competência, assegurar a promoção da segurança epidemiológica, garantir a equidade, a promoção da saúde e o 
desenvolvimento de todas as crianças, e, ainda, criar estratégias de trabalho intersetoriais. A saída para a justiça social é, assim, entre outras ações, a intersetorialidade.

\section{REFERÊNCIAS}

ALMEIDA FILHO, Naomar de. Volta às aulas com COVID. [S. l.], 16 fev. 2021. Facebook: CNTE. Disponível https://www.facebook.com/watch/live/?v $=165287708558567 \&$ ref $=$ watch permalink. Acesso em 2 mar. 2021.

ANPED. Associação Nacional de Pós-Graduação e Pesquisa em Educação. Saúde, Educação e Assistência Social: perspectivas de enfrentamento à pandemia. ANPEd Nacional, 24 fev. 2021. 1 vídeo (1h19min20s). Disponível em https://www.youtube.com/watch?v=L5cjWWDB2b4. Acesso em 2 mar. 2021.

ASSIS, Marluci Maria Araújo et al. Atenção primária à saúde e sua articulaşão com a Estratégia Saúde da Família: construção política, metodológica e prática. 2007. Disponível em http://www5.ensp.fiocruz.br/biblioteca/dados/txt 228616371.pdf. Acesso em 2 mar. 2021.

BÖCK, Geisa Letícia Kempfer; GOMES, Débora Marques; BECHE, Rose Clér Estivalete. A experiência da deficiência em tempos de pandemia e ética do cuidado. Revista Criar Educação, Criciúma, v. 9, n. 2., edição especial, 2020. DOI: http://dx.doi.org/10.18616/ce.v9i2.6049.

BRASIL. Programa de Capacitação de Recursos Humanos do Ensino Fundamental: Deficiência Múltipla. Brasília: Ministério da Educação, Secretaria de Educação Especial, 2000. (Série Atualidades Pedagógicas).

BRASIL. Política Nacional de Educação Especial na perspectiva da Educação Inclusiva. Brasília: MEC, 2008.

BRASIL. Portaria n. 3.502 de 19 de dezembro de 2017. Institui, no âmbito do Sistema Único de Saúde - SUS, a Estratégia de fortalecimento das ações de cuidado das crianças suspeitas ou confirmadas para Síndrome Congênita associada à infecção pelo vírus Zika e outras síndromes causadas por sífilis, toxoplasmose, rubéola, citomegalovírus e herpes vírus. Brasília: Ministério da Saúde, [2017]. Disponível em http://www.saude.ba.gov.br/wp-content/uploads/2018/04/PORTARIA-N3.502-DE-19-DE-DEZEMBRO-DE-2017.pdf. Acesso em 3 mar. 2021.

BRONFENBRENNER, Urie. Bioecologia do desenvolvimento bumano: tornando os seres humanos mais humanos. Porto Alegre: Artmed, 2012.

CAIVANO, Fabricio. Prefácio. In: TORRES, Rosa Maria (ed.). Itinerários pela Educaşão Latino Americana. Porto Alegre: Artmed, 2001. p. 9-13.

CAMPOS, Gastão Wagner de Sousa. A mediação entre conhecimento e práticas sociais: a racionalidade da tecnologia leve, da práxis e da arte. Ciência \& Saúde Coletiva, Rio de Janeiro, v. 16, n. 7, p. 3033-3040, 2011. DOI: https://doi.org/10.1590/S1413-81232011000800002.

CARVALHO, Fabio Fortunato Brasil. de. A saúde na escola e a promoção da saúde: conhecendo a dinâmica intersetorial em Duque de Caxias e Nova Iguaçu - RJ. 2012. 115 f. Dissertação (Mestrado em Ciências na área de Saúde Pública), Escola Nacional de Saúde Pública Sérgio Arouca, Fiocruz, Rio de Janeiro, 2012.

DAINEZ, Débora; SMOLKA, Ana Luiza Bustamante. A função social da escola em discussão, sob a perspectiva da educação inclusiva. Educação e Pesquisa, São Paulo, v. 45, p. 1-18, 2019. DOI: http://dx.doi.org/10.1590/s1678-4634201945187853. 
DIAS, Maria Socorro de Araújo et al. Intersetorialidade e Estratégia Saúde da Família: tudo ou quase nada a ver? Revista Ciência \& Saúde Coletiva, Rio de Janeiro, v. 19, n. 11, p. 4371-4382, 2014. DOI: https://doi.org/10.1590/1413-812320141911.11442014.

DUSSEL, Inés. La escuela en la pandemia. Reflexiones sobre lo escolar en tiempos dislocados. Práxis Educativa, Ponta Grossa, v. 15, e2016482, p. 1-16, 2020. DOI: https://doi.org/10.5212/PraxEduc.v.15.16482.090.

FIETZ, Helena Moura; MELLO, Anahi Guedes de. A multiplicidade do cuidado na experiência da deficiência. Revista ANTHROPOLÓGICAS, Recife, ano 22, v. 29, n. 2, p. 114-141, 2018.

FRASER, Nancy. Da redistribuição ao reconhecimento? Dilemas. Cadernos de Campo, São Paulo, n. 14/15, p. 1-382, 2006.

GIONGO, Maria José Domingues da Silva. Cultura da paそ, cidadania e direitos humanos na promoção da saúde: a experiência de quatro escolas no Programa Saúde na Escola no Município de Duque de Caxias. 2019. 233 f. Tese (Doutorado em Ciências na área de Saúde Pública), Escola Nacional de Saúde Pública Sérgio Arouca, Fiocruz, Rio de Janeiro, 2019.

GUIMARÃES, Cátia. Antes, durante e depois da pandemia: que país é esse? Revista Poli, Rio de Janeiro, v. 13, n. 73, p. 6-12, set./out. 2020.

HODGETTS, Sandra et al. Parents' and professionals' perceptions of family-centered care for children with autism spectrum disorder across service sectors. Social Science \& Medicine, [s. l.], n. 96, p. 138-146, 2013. DOI: 10.1016/j.socscimed.2013.07.012.

IPFCC. Institute for Patient and Family-Centered Care. Advancing the practice of patient and familycentered care in bospitals: how to get started. 2014. Disponível em http://www.ipfcc.org/about/mission.html . Acesso em 3 mar. 2021.

MOREIRA, Martha Cristina Nunes et al. Recomendações para uma linha de cuidados para crianças e adolescentes com condições crônicas complexas de saúde. Cadernos de Saúde Pública, Rio de Janeiro, v. 33, n. 11, e00189516, p. 1-13, 2017. DOI: https://doi.org/10.1590/0102$\underline{311 \times 00189516 .}$

MOREIRA, Martha Cristina Nunes et al. Adoecimentos raros e o diálogo associativo: Ressignificações para experiências morais. Ciência \& Saúde Coletiva, v. 24, p. 3673-3682, jul. 2019. DOI: https://doi.org/10.1590/1413-812320182410.11822019.

OMS. Organização Mundial da Saúde. Cuidados inovadores para condições crônicas: componentes estruturais de ação. Brasília: OMS, 2003.

OMS. Organização Mundial da Saúde. International classification of functioning, disability and health: Children \& youth version; ICF-CY. Geneva: World Health Organization, 2007.

PAHO, WHO. Pan American Health Organization. World Health Organization. WHO remains firmly committed to the principles set out in the preamble to the Constitution. 2016. Disponivel em https://www.who.int/about/who-we-are/constitution. Acesso em 3 mar. 2021.

PLETSCH, Márcia Denise. Deficiência múltipla: formação de professores e processos de ensinoaprendizagem. Cadernos de Pesquisa, São Paulo, v. 45, n. 155, p. 12-29, jan./mar. 2015. DOI: http://dx.doi.org/10.1590/198053142862.

PLETSCH, Márcia Denise. Pesquisas e ações intersetoriais entre educação e saúde na promoção da escolarização e do desenvolvimento de crianças com síndrome congênita do Zika vírus na Baixada Fluminense. Projeto de Pesquisa. Nova Iguaçu: UFFRJ, 2019. 
DOI: $10.12957 /$ teias.2021.58619

PLETSCH, Márcia Denise. O que há de especial na Educação Especial Brasileira? Momento Diálogos em Educação, v. 29, n. 1, p. 1-15, 2020. DOI: https://doi.org/10.14295/momento.v29i1.9357.

PLETSCH, Márcia Denise; ARAUJO, Patricia Cardoso Macedo do Amaral; ROCHA, Maíra Gomes de Souza da. A importância de ações intersetoriais como estratégia para a promoção da escolarização de crianças com a síndrome congênita do zika vírus (SCZV). Revista Educação em Foco, Juiz de Fora, v. 25, n. 3, p. 193-210, 2020. DOI: https://doi.org/10.22195/2447$\underline{524620202532924 .}$

PLETSCH, Márcia Denise; MENDES, Geovana Mendonça Lunardi. Entre a espera e a urgência: propostas educacionais remotas para crianças com Síndrome Congênita do Zika Vírus durante a pandemia da COVID-19. Revista Práxis Educativa, Ponta Grossa, v. 15, e2015335, p. 1-16, 2020. DOI: https://doi.org/10.5212/PraxEduc.v.15.17126.106.

PLETSCH, Márcia Denise; MENDES, Geovana Mendonça Lunardi; HOSTINS, Regina Célia Linhares (org.). A escolarização de alunos com deficiência intelectual: políticas, práticas e processos cognitivos. Marília: M\&M/ABPEE, 2015.

PLETSCH, Márcia Denise; SOUZA, Flávia Faissal de. Educação comum ou especial? Análise das diretrizes políticas de Educação Especial brasileiras. Revista Ibero-Americana de Estudos em Educação, Araraquara, 2021. (No prelo).

PLETSCH, Márcia Denise; ROCHA, Maíra Gomes de Souza da; OLIVEIRA, Mariana Corrêa Pitanga de. Propostas pedagógicas para alunos com deficiência intelectual e múltipla: análises de cenas do cotidiano escolar. Revista Educação, Ciência e Cultura, Canoas, v. 25, v. 1, p. 33-46, 2020. DOI: http://dx.doi.org/10.18316/recc.v25i1.6271.

RIO DE JANEIRO. Nota técnica conjunta n. 001SEASDH-RJ e SES-RJ. Rio de Janeiro: Secretaria de Estado de Assistência Social e Direitos Humanos. Secretaria de Estado de Saúde, 2016.

ROCHA, Maíra Gomes de Souza da. Processos de ensino e aprendizagem de alunos com múltiplas deficiências no AEE à luz da teoria bistórico-cultural. 2014. 218 f. Dissertação (Mestrado em Educação) - Instituto de Educação e Instituto Multidisciplinar, Universidade Federal Rural do Rio de Janeiro, Nova Iguaçu, 2014.

ROCHA, Maíra Gomes de Souza da. Os sentidos e significados da escolarização de sujeitos com deficiência múltipla. 2018. 308 f. Tese (Doutorado em Educação) - Universidade Federal Rural do Rio de Janeiro, Nova Iguaçu, 2018.

SÁ, Miriam Ribeiro Calheiros de; PLETSCH, Márcia Denise. A participação de crianças com a Síndrome Congênita do Zika Vírus: intercessões entre o modelo bioecológico e a funcionalidade humana. Práxis Educativa, Ponta Grossa, v. 16, e2117383, p. 1-15, 2021. DOI: https://doi.org/10.5212/PraxEduc.v.16.17383.017.

SÁ, Miriam Ribeiro Calheiros de et al. De toda maneira tem que andar junto: ações intersetoriais entre saúde e educação para crianças vivendo com a síndrome congênita do vírus Zika. Cadernos de Saúde Pública, Rio de Janeiro, v. 35, n. 12, e00233718, p. 1-13, 2019. DOI: http://dx.doi.org/10.1590/0102-311x00233718.

SATO, Michèle (org.). Os condenados da pandemia. Cuiabá: GPEA-UFMT, 2020.

SANTOS, Debora de Souza; MISHIMA, Silvana Martins; MERHY, Emerson Elias. Processo de trabalho na Estratégia de Saúde da Família: potencialidades da subjetividade do cuidado para 
reconfiguração do modelo de atenção. Ciência \& Saúde Coletiva, Rio de Janeiro, v. 23, n. 3, p. 861870, 2018. DOI: https://doi.org/10.1590/1413-81232018233.03102016.

SENNA, Luiz Antonio Gomes. O campo acadêmico do letramento e da alfabetização no Brasil: Estados e perspectivas da pesquisa em linguística aplicada. Revista Teias, Rio de Janeiro, v. 15, n. 38, p. 57-74, 2014.

SILVA, Kênia Lara; RODRIGUES, Andreza Trevenzoli. Ações intersetoriais para promoção da saúde na Estratégia Saúde da Família: experiências, desafios e possibilidades. Revista Brasileira de Enfermagem, Brasília, v. 63, n. 5, p. 762-769, 2010. DOI: https://doi.org/10.1590/S0034$\underline{71672010000500011 .}$

SOUZA, Flávia Faissal de. As pessoas com deficiência e a educação: políticas sociais e de educação inclusiva nos governos do PT (2003-2011). Agenda Social, Campos dos Goytacazes, v. 10, n. 1, p. 44-59, 2017.

TEIXEIRA, Carmen Fontes; PAIM, Jairnilson Silva. Planejamento e programação de ações intersetoriais para a promoção da saúde e da qualidade de vida. In: TEIXEIRA, Carmen Fontes; PAIM, Jairnilson Silva; VILASBOAS, Ana Luiza (org.). Promoşão e vigilância da saúde. Salvador: Instituto de Saúde Coletiva, 2002. p. 59-78.

UNESCO. Organização das Nações Unidas para a Educação, a Ciência e a Cultura. Monitoramento Mundial do Fechamento das Escolas devido ao COVID. 2020. Disponível em https://pt.unesco.org/covid19/educationresponse. Acesso em 12 nov. 2020.

UNESCO. United Nations Educational, Scientific and Cultural Organization. Global education monitoring report, 2020: Inclusion and education: all means all. 2020a. Disponível em https://unesdoc.unesco.org/ark:/48223/pf0000373718?posInSet=1\&queryId=11cd824e-092d4abe-82ad-1c70a08ca632. Acesso em 12 nov. de 2020.

VAN VEELEN, Jeanine S. M. et al. Embedding the notion of child-and family-centered care into organizational practice: Learning from organizational visioning. Journal of Public Child Welfare, [s. l.], v. 11, n. 2, p. 231-259. DOI: https://doi.org/10.1080/15548732.2016.1267068.

VIEIRA, Lidiane Sales; BELISÁRIO, Soraya Almeida. Intersetorialidade na promoção da saúde escolar: um estudo do Programa Saúde na Escola. Saúde em Debate, Rio de Janeiro, v. 42, n. esp. 4, p. 120-133, dez. 2018. DOI: https://doi.org/10.1590/0103-11042018s409.

VYGOTSKI, Lev Semionovich. Obras escogidas volume 5: Fundamentos da defectologia. Madrid: Visor, 1997.

WIMMER, Gert Ferreira; FIGUEIREDO, Gustavo de Oliveira. Ação coletiva para qualidade de vida: autonomia, transdisciplinaridade e intersetorialidade. Revista Ciência \& Saúde Coletiva, Rio de Janeiro, v. 11, n. 1, p. 145-154. 2006. DOI: https://doi.org/10.1590/S1413-81232006000100022.

Submetido em fevereiro de 2021 Aprovado em maio de 2021 


\section{Informações das autoras}

Márcia Denise Pletsch

Professora do Programa de Pós-Graduação em Educação, Contextos Contemporâneos e Demandas Populares (PPGEduc) e do Programa de Pós-Graduação em Humanidades Digitais da Universidade Federal Rural do Rio de Janeiro (UFRRJ).

E-mail: marciadenisepletsch@gmail.com

ORCID: https://orcid.org/0000-0001-5906-0487

Link Lattes: http://lattes.cnpq.br/5622440291569151

Miriam Ribeiro Calheiros de Sá

Professora colaboradora no Programa de Pós-Graduação stricto sensu Saúde da Mulher e da Criança IFF/Fiocruz. Pesquisadora do Observatório de Educação Especial e Inclusão Educacional (ObEE) da Universidade Federal Rural do Rio de Janeiro (UFRRJ).

E-mail: calheirosa@uol.com.br

ORCID: http://orcid.org/0000-0002-3972-0377

Link Lattes: http://lattes.cnpq.br/2235642043560899

Geovana Mendonça Lunardi Mendes

Professora do Programa de Pós-Graduação em Educação (PPGE) da Universidade do Estado de Santa Catarina (UDESC). Presidenta (gestão 2019-2021) da Associação Nacional de Pós-Graduação e Pesquisa em Educação (ANPEd).

E-mail: geolunardi@gmail.com

ORCID: https://orcid.org/0000-0002-8848-7436

Link Lattes: http://lattes.cnpq.br/6078460594205572 